\title{
MOVIMENTAÇÃO DE NITRATO E AMÔNIO EM COLUNAS DE SOLO
}

\author{
Nitrate and ammonium movement in soil columns \\ Alexandre Romeiro de Araújo ${ }^{1}$, João Luís Nunes Carvalho², \\ Luiz Roberto Guimarães Guilherme ${ }^{3}$, Nilton Curi ${ }^{3}$, João José Marques ${ }^{3}$
}

\section{RESUMO}

No sistema de plantio convencional, a prática anual de revolvimento do solo provoca alterações nas propriedades físicas, como diminuição da porosidade, modificação da estabilidade de agregados e destruição dos canais deixados pelo sistema radicular. No sistema de plantio direto, não há revolvimento do solo. Portanto, a aplicação de calcário, assim como de N, deve ser feita em superfície, em razão da impossibilidade de sua aplicação em profundidade. Objetivou-se com este trabalho estudar a movimentação de $\mathrm{NO}_{3}^{-}$e $\mathrm{NH}_{4}^{+}$em colunas de solo indeformado, com e sem aplicação de calcário. Conduzido em casa-devegetação, utilizaram-se tubos de PVC com 0,2 m de diâmetro e 0,2 m de comprimento. As amostras de um Latossolo Vermelho Distrófico típico de textura muito argilosa, localizado no campus da UFLA, foram retiradas do horizonte A (0-0,2 m) indeformadas. A irrigação e a análise do lixiviado foram feitas diariamente. No lixiviado, foram medidos o $\mathrm{NO}_{3}^{-}$e o $\mathrm{NH}_{4}^{+}$. As análises de nitrato foram feitas por dois métodos diferentes, sendo um pela redução do nitrito na coluna de $\mathrm{Cd}-\mathrm{Cu}$ e o outro por um eletrodo seletivo; as análises de $\mathrm{NH}_{4}^{+}$foram feitas pelo método do Nessler. O delineamento experimental utilizado foi o delineamento inteiramente casualizado, com três repetições. Mesmo com doses realistas de adubos nitrogenados (200 kg $\mathrm{N}^{-}$ $\left.{ }^{1}\right)$ e em Latossolos muito argilosos, com moderados a altos teores de óxidos de Fe e gibbsita, a lixiviação de $\mathrm{NO}_{3}^{-}$é uma realidade.

Termos para indexação: Lixiviação, nitrogênio, colunas de solo.

\section{ABSTRACT}

In the conventional tillage, the annual practice of revolving the soil leads to modifications in the soil physical properties as decrease of the porosity, modification of aggregate stability and destroction of the channels left by the root system. In the no-till system, there is no revolving of the soil. Therefore, liming as well as nitrogen fertilization applied must be made on the surface due to impossibility of this application in depth. The objective of this work was to study the movement of $\mathrm{NO}_{3}^{-}$ and $\mathrm{NH}_{4}^{+}$in undisturbed soil columns, with and without liming application. The present study was carried out in the greenhouse using PVC tubes of $0.2 \mathrm{~m}$ of diameter and $0.2 \mathrm{~m}$ of length using a very clayey typical dystroferric Red Latosol, located in the UFLA campus. The undisturbed soil samples were taken in the A horizon $(0-0.2 \mathrm{~m})$. The irrigation and the analyses of the leached water were made daily. In the leached water, it were measured $\mathrm{NO}_{3}^{-}$and $\mathrm{NH}_{4}^{+}$. The $\mathrm{NO}_{3}^{-}$analysis were done by two different methods. The first one is based on the $\mathrm{NO}_{3}^{-}$reduction to $\mathrm{NO}_{2}^{-}$in a Cd-Cu column. The second method used a selective electrode. The $\mathrm{NH}_{4}^{+}$were done by the Nessler method. The experimental design was the complete randomized, with three replications. Even with usual doses of $\mathrm{N}\left(200 \mathrm{~kg} \mathrm{ha}^{-1}\right)$ amendments in a very clayey Latosols, with moderate to high $\mathrm{Fe}$ and $\mathrm{Al}$ oxide content, $\mathrm{NO}_{3}^{-}$leaching was observed.

Index terms: Leaching, nitrogen, soil columns.

(Recebido para publicação em 26 de maio de 2003 e aprovado em 3 de setembro de 2003)

\section{INTRODUÇÃO}

Uma preocupação em âmbito mundial é a contaminação de recursos hídricos com nitrato percolado de solos agrícolas. A grande mobilidade do íon $\mathrm{NO}_{3}^{-}$no solo, aliada à crescente utilização de fertilizantes minerais nitrogenados, gera uma grande preocupação em diversas áreas do planeta, por causa da eutrofização de águas superficiais e da contami-

\footnotetext{
1. Mestrando em Solos e Nutrição de Plantas do Departamento de Ciência do Solo da Universidade Federal de Lavras/UFLA - Caixa Postal 37 - 37200 000 - Lavras, MG.

2. Bolsista de Iniciação Científica - CNPq.

3. Professor do Departamento de Ciência do Solo da UFLA.
} 
nação de águas subterrâneas, as quais, muitas vezes, são a principal fonte desse recurso natural para grandes populações (MUCHOVEJ e RECHCIGL, 1995).

A poluição das águas e do solo constitui-se num dos mais sérios problemas ecológicos decorrentes da atividade humana da atualidade. Os fertilizantes usados na agricultura contêm grandes concentrações de N e P. Esses elementos são importantes nutrientes para as plantas, inclusive para as plantas aquáticas, especialmente as algas. Em condições de abundância de $\mathrm{N}$ e $\mathrm{P}$, as algas crescem excessivamente. A decomposição dessas algas por microrganismos saprófitas consome oxigênio em demasia, podendo prejudicar outras formas de vida aquática, como peixes. A esse fenômeno, dá-se o nome de eutrofização.

Embora inicialmente fosse julgado que as perdas de $\mathrm{NO}_{3}^{-}$por lixiviação em solos brasileiros fossem mínimas (Vitousek, 1983; Reis e Barros, 1990), devido à existência de cargas elétricas positivas em profundidade no solo (Dynia, 2000), verifica-se em estudos recentes que mesmo Latossolos podem apresentar lixiviação de nitrato. Oliveira et al. (2001) observaram perdas acima de $100 \mathrm{~kg} \mathrm{NO}_{3}^{-}$ ha-1 ano-1 em solos que receberam lodo de esgoto ou mesmo adubação nitrogenada convencional para a cultura da cana-de-açúcar. Lixiviação de $\mathrm{NO}_{3}^{-}$ dessa magnitude representa um óbvio problema ambiental. Mesmo em solos eletropositivos e com alto teor de argila, Dynia (2000) observou que o $\mathrm{NO}_{3}^{-}$ movimentava-se além da zona de exploração radicular da maioria das culturas, alcançando profundidades entre 2 e $6 \mathrm{~m}$ e acumulando-se aí. Além disso, a lixiviação de $\mathrm{NO}_{3}^{-}$também contribui para aumentar a lixiviação de $\mathrm{Ca}$ e $\mathrm{Mg}$ (Cahn et al., 1993).

Realizou-se este trabalho com o objetivo de estudar a movimentação de $\mathrm{NO}_{3}^{-}$e $\mathrm{NH}_{4}^{+}$em colunas de solo indeformado, com e sem aplicação de calcário.

\section{MATERIAL E MÉTODOS}

O solo utilizado no experimento foi o horizonte A de um Latossolo Vermelho distroférrico típico, textura muito argilosa $\left(770 \mathrm{~g} \mathrm{~kg}^{-1}\right)$, localizado no Campus da UFLA, com $234 \mathrm{~g} \mathrm{~kg}^{-1}$ de $\mathrm{Fe}_{2} \mathrm{O}_{3}$ na TFSA, determinado por ataque sulfúrico, e com 308 $\mathrm{g} \mathrm{kg}^{-1}$ de gibbsita na TFSA, determinado por análise termo-diferencial.

As colunas utilizadas neste experimento possuíam $0,20 \mathrm{~m}$ de diâmetro por $0,20 \mathrm{~m}$ de altura. Para que essas colunas fossem retiradas do solo indeformadas, utilizou-se um anel de aço inox, que era acoplado em sua base, de modo a facilitar a penetração das colunas no solo, causando, assim, uma perturbação mínima na estrutura original do solo.

$\mathrm{O}$ volume de poros foi calculado pela fórmula:

$$
\mathrm{VTP}=\left(1-\frac{\mathrm{Ds}}{\mathrm{Dp}}\right) \times 100
$$

Em que: VTP é o volume total de poros; Ds, a densidade do solo; e Dp, a densidade de partículas. Os tratamentos utilizados foram os seguintes:

Tratamento 1 - testemunha (T)

Tratamento 2 - calcário superficial com uréia (CSU)

Tratamento 3 - sem calcário com uréia (U).

A dose de calcário utilizada foi de 1,5 $\mathrm{t} \mathrm{ha}^{-1}$. Em se tratando de calagem superficial, segundo Lopes (1999), essa dose pode ser dividida por três quando se trata de amostragem de 0 a 0,2 m. Assim, a dose encontrada foi dividida por três, sendo calculada pelo método da saturação por bases ( $5^{\text {a }}$ aproximação) para elevá-la a $70 \%$. Assim, a dose aplicada foi $0,5 \mathrm{t} \mathrm{ha}^{-1}$, o que equivale a 1,57 g por coluna que recebeu o calcário. O calcário foi aplicado superficialmente no dia do início do experimento. A dose de uréia utilizada foi de $200 \mathrm{~kg} \mathrm{~N}$ $\mathrm{ha}^{-1}$, o que equivale a $0,674 \mathrm{~g}$ por coluna de PVC, parcelados em duas vezes: no início do experimento e 15 dias depois.

A irrigação, com água desmineralizada, neste ensaio foi de aproximadamente $1000 \mathrm{~mL}$ a cada dois dias. Durante os 30 dias de duração do experimento, em dias alternados, aplicaram-se $250 \mathrm{~mL}$ quatro vezes ao dia, em intervalos de três horas, iniciando-se às 7 horas. A quantidade irrigada ao final do ensaio foi equivalente a $\sim 480 \mathrm{~mm}$ de precipitação.

O volume lixiviado era coletado diariamente. Nas amostras de lixiviado, foram feitas, a cada dois dias, análises de $\mathrm{NO}_{3}^{-}$, pelos métodos da redução a $\mathrm{NO}_{2}^{-}$em coluna de $\mathrm{Cu}-\mathrm{Cd}$, e pelo eletrodo seletivo. $\mathrm{O}$ $\mathrm{NH}_{4}^{+}$foi determinado pelo método de Nessler (APHA, 1989). O delineamento experimental utilizado foi o inteiramente casualizado, com três repetições. 


\section{RESULTADOS E DISCUSSÃO}

Neste trabalho, a lixiviação de $\mathrm{NO}_{3}^{-}$e $\mathrm{NH}_{4}^{+}$ foi medida nos tratamentos em que foi aplicada uréia, com e sem calcário, e na testemunha. Esses tratamentos foram identificados pela sigla T, CSU e U. Vale ainda lembrar que foram utilizados dois métodos para medir o teor de $\mathrm{NO}_{3}^{-}$, sendo um deles pelo método da coluna de $\mathrm{Cd}-\mathrm{Cu}$ e o outro por eletrodo seletivo.

Na Figura 1, observa-se uma grande variabilidade nos dados de $\mathrm{NH}_{4}^{+}$em relação aos tratamentos em questão, não sendo possível detectar tendências claras. Os tratamentos que receberam uréia apresentaram uma alta lixiviação de $\mathrm{NH}_{4}^{+} \operatorname{logo}$ no início do experimento. Após isso, houve, contudo, uma menor lixiviação de $\mathrm{NH}_{4}^{+}$no tratamento que recebeu uréia e calcário (CSU). O aumento das cargas negativas do solo, gerado pela calagem, pode ter contribuído para maior retenção de $\mathrm{NH}_{4}^{+}$. Por outro lado, o maior $\mathrm{pH}$ gerado pela calagem pode levar a perdas de $\mathrm{NH}_{4}^{+}$por volatilização de $\mathrm{NH}_{3}$.

Na Figura 2, observa-se a quantidade de $\mathrm{NO}_{3}^{-}$ lixiviado no ensaio pelo método da coluna de $\mathrm{Cd}-\mathrm{Cu}$, em que se nota que a quantidade de $\mathrm{NO}_{3}^{-}$tende a aumentar com o aumento do volume de poros percolados. Nota-se, ainda, que no tratamento que recebeu uréia e calcário (CSU), a lixiviação de $\mathrm{NO}_{3}^{-}$foi maior, no decorrer do ensaio, em relação ao tratamento que recebeu apenas uréia, sendo esses tratamentos visivelmente superiores à testemunha. Nota-se na Figura 3, em que também foi analisado o $\mathrm{NO}_{3}^{-}$, só que pelo eletrodo seletivo, que essa tendência exibiu resultados semelhantes.

Houve uma tendência, contudo, de o método do eletrodo produzir resultados maiores. Davenport e Jabro (2001) também concluíram que o método do eletrodo superestima o teor de $\mathrm{NO}_{3}^{-}$em solos. No presente estudo, $\mathrm{NO}_{3}^{-}$foi medido em lixiviados e, apesar de também ter superestimado as concentrações de $\mathrm{NO}_{3}^{-}$, tal superestimação não foi grosseira. No presente experimento, o eletrodo de $\mathrm{NO}_{3}^{-}$mostrou-se compensador, pela facilidade de uso, rapidez e baixo custo.

Corroborando com Ernani et al. (2001), a lixiviação máxima de $\mathrm{N}$ está de acordo com os encontrados pelos pesquisadores acima citados, isto é, o pulso de $\mathrm{NO}_{3}^{-}$ocorreu mais tarde. Isso obviamente pode ter ocorrido devido à forma de como $\mathrm{N}$ foi aplicado. Neste trabalho, aplicou-se na forma de uréia, assim como no caso dos pesquisadores acima citados. Houve, portanto, um certo tempo necessário para a reação de oxidação.

Binkley et al. (1999) afirmam que, em condições de campo, a oxidação de $\mathrm{NH}_{4}^{+}$em $\mathrm{NO}_{3}^{-}$ocorre num prazo de semanas ou meses. Pelos dados do presente estudo, embora em condições de casa-devegetação, observa-se que tal reação pode ocorrer num prazo mais rápido. Pelos resultados, verifica-se que a transformação do $\mathrm{N}-\mathrm{NH}_{2}$ da uréia em $\mathrm{NO}_{3}^{-}$ ocorreu por volta de uma semana após a aplicação desse fertilizante. Existe, contudo, a possibilidade de que esse $\mathrm{NO}_{3}^{-}$tenha vindo não da uréia, mas sim da decomposição da matéria orgânica do solo, estimulada pela aplicação da uréia.

Nos tratamentos em que se utilizou calcário + uréia (CSU), a lixiviação de $\mathrm{NO}_{3}^{-}$foi superior à do tratamento que recebeu apenas uréia (U) (Figura 2). Uma explicação concorre para isso: o calcário aumenta a quantidade de cargas negativas no solo, favorecendo a movimentação de ânions. Apesar de a lixiviação de $\mathrm{NO}_{3}^{-}$ter sido maior no tratamento (CSU) em ambos os tratamentos, essa lixiviação, por vezes, ultrapassou o limite de $10 \mathrm{mg} \mathrm{N} \mathrm{L}^{-1}$, estabelecido pela legislação americana como o nível máximo de $\mathrm{NO}_{3}^{-}$permitido para águas destinadas ao consumo humano. 


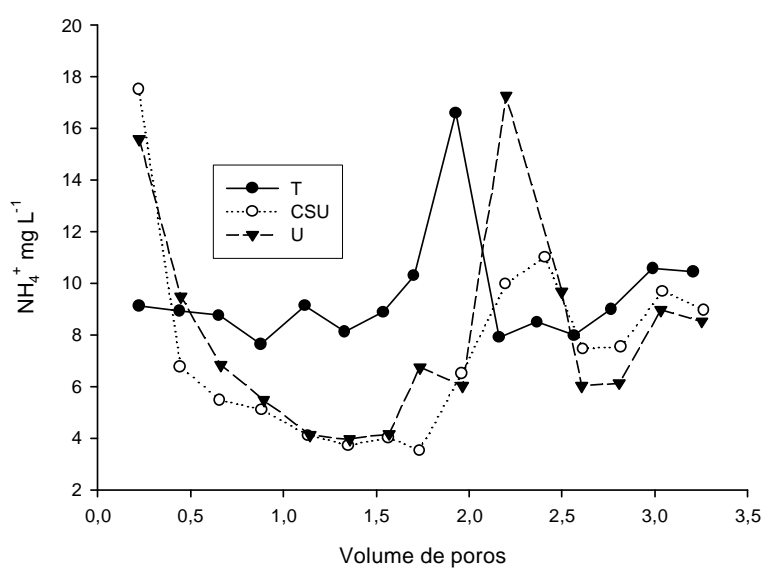

FIGURA 1 - Concentração de $\mathrm{NH}_{4}^{+}$no lixiviado.

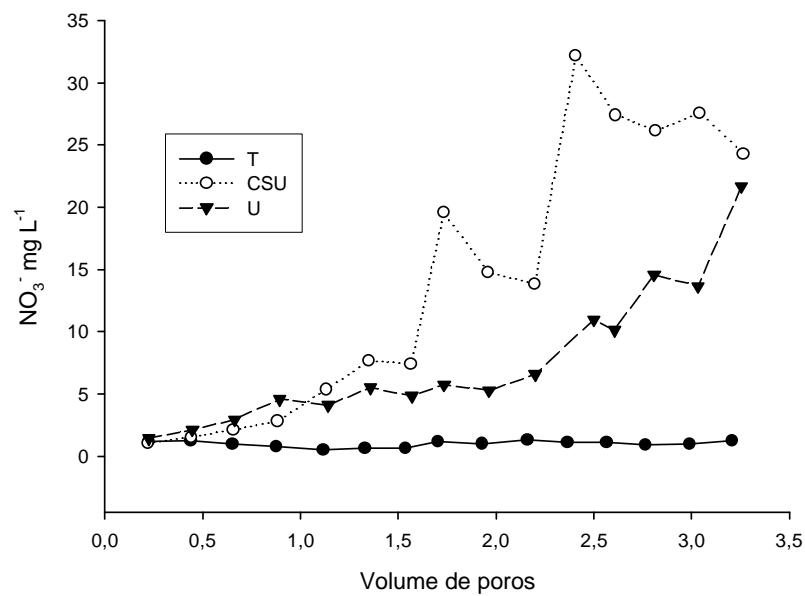

FIGURA 2 - Concentração de $\mathrm{NO}_{3}^{-}$do lixiviado pelo método da coluna de $\mathrm{Cd}-\mathrm{Cu}$.

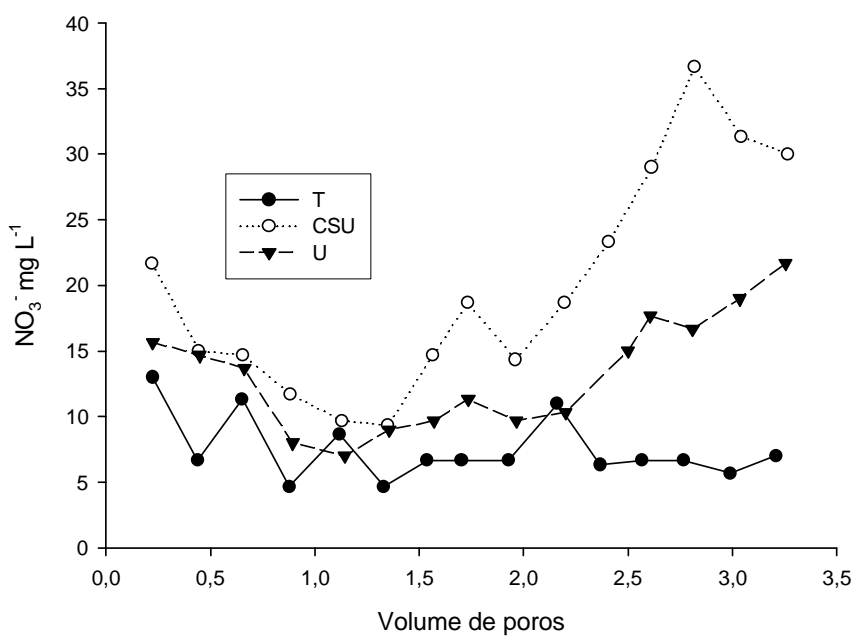

FIGURA 3 - Concentração de $\mathrm{NO}_{3}^{-}$do lixiviado pelo método do eletrodo seletivo.

Ciênc. agrotec., Lavras, v. 28, n. 3, p. 537-541, maio/jun., 2004 


\section{CONCLUSÕES}

Mesmo com doses realistas de adubos nitrogenados e em Latossolos muito argilosos, com altos teores de óxidos de $\mathrm{Fe}$ e gibbsita, a lixiviação de $\mathrm{NO}_{3}^{-}$e $\mathrm{NH}_{4}^{+}$é uma realidade. Isso implica em maiores cuidados no manejo da adubação nitrogenada em razão das enormes implicações econômicas e ambientais envolvidas.

\section{REFERÊNCIAS BIBLIOGRÁFICAS}

AMERICAN PUBLIC HEALTH ASSOCIATION. Standard methods for the examination of water and wastewater. 17. ed. Washington, 1989.

BINKLEY, D.; HEATHER BURNHAN; ALLEN, H. L. Water quality impacts of forest fertilization with nitrogen and phosphorus. Forest Ecology and Management, Amsterdam, v. 121, p. 191-213, 1999.

CAHN, M. D.; BOULDIN, D. R.; CRAVO, M. S.; BOWEN, M. T. Cation and nitrate leaching in an Oxisol of the Brazilian Amazon. Agronomy Journal, Madison, v. 85, n. 2, p. 334-340, Mar./Apr. 1993.

DAVENPORT, J. R.; JABRO, J. D. Assessment of hand held ion selective electrode technology for direct measurement of soil chemical propertieis. Communications Soil Science in Plant Analysis, New York, v. 32, n. 5/6, p. 3077-3085, 2001.

DYNIA, J. F. Nitrate retention and leaching in variable charge soils of a watershed in São Paulo State, Brazil. Communications Soil Science in Plant Analysis, New York, v. 31, n. 5/6, p. 777-791, 2000.
ERNANI, P. R.; RIBEIRO, M. S.; BAYER, C. Modificações químicas em solos ácidos ocasionadas pelo método de aplicação de corretivos da acidez e de gesso agrícola. Scientia Agricola, Piracicaba, v. 58, n. 4, p. 825-831, out./dez. 2001.

LOPES, A. S. Recomendações de calagem e adubação no sistema de plantio direto. In: RIBEIRO, A. C.; GUIMARÃES, P. T. G.; ALVARES, V. H. (Orgs.). Recomendação para o uso de corretivos e fertilizantes em Minas Gerais: $5^{\underline{a}}$ aproximação. Viçosa: UFV/EPAMIG, 1999. 359 p.

MUCHOVEJ, R. M. C.; RECHCIGL, J. E. Nitrogen fertilizants. In: RECHCIGL, J. E. (Ed.). Soil Amendments and environmental quality. Boca Raton: Lewis, 1995. p. 1-64.

OLIVEIRA, F. C.; MATTIAZZO, M. E.; MARCIANO, C. R.; MORAES, S. O. Lixiviação de nitrato em um Latossolo Amarelo distrófico tratado com lodo de esgoto e cultivado com cana-de-açúcar. Scientia Agricola, Piracicaba, v. 58, n. 1, p. 171-180, jan./mar. 2001.

REIS, M. G. F.; BARROS, N. F. Ciclagem de nutrientes em plantios de eucalipto. In: BARROS, N. F.; NOVAIS, R. F. Relação solo-eucalipto. Viçosa: Folha de Viçosa, 1990. p. 265-301.

VITOUSEK, P. M. The effects of deforestation on air, soil, and water. In: BOLIN, B.; COOK, R. B. (Eds.). The major biogeochemical cycles and their interactions. Chichester: Wiley, 1983. p. 223245. 